\title{
miRNA-129-5p suppresses cell proliferation and invasion in lung cancer by targeting microspherule protein 1, E-cadherin and vimentin
}

\author{
YONGZHOU ZHANG ${ }^{1 *}$, JIHONG AN $^{1 *}$, WEILING LV ${ }^{1}$, TINGTING LOU ${ }^{1}$, YUNXIN LIU ${ }^{1}$ and WENYI KANG ${ }^{1,2}$ \\ ${ }^{1}$ Department of Pharmacy, Huaihe Hospital; ${ }^{2}$ Institute of Natural Products, \\ Henan University, Kaifeng, Henan 475001, P.R. China
}

Received June 18, 2015; Accepted October 24, 2016

DOI: $10.3892 / \mathrm{ol} .2016 .5372$

\begin{abstract}
Downregulation of microRNA-129 (miR-129) has been described in various types of cancer, however, the significance of miR-129 in lung cancer has not been investigated. The present study, for the first time, determined miR-129-5p expression levels in both lung cancer cell lines and primary lung cancer tissues and also studied the effect of miR-129-5p on the proliferation and invasiveness of lung cancer cells. The results showed that miR-129-5p expression was significantly reduced in both lung cancer cell lines and primary lung cancer tissues $(\mathrm{P}<0.05)$. Further research revealed that miR-129-5p could suppress the proliferation and invasion capability of lung cancer cells. Bioinformatics analysis suggested three cancer-related miR-129-5p target genes: Microspherule protein 1 (MCRS1), E-cadherin and vimentin. Further investigation via reverse transcription-quantitative polymerase chain reaction and western blot analysis showed that miR-129-5p was able to reduce the expression levels of MCRS1 and vimentin and enhance the expression of E-cadherin at both the messenger RNA and protein levels. The present results indicate that miR-129-5p is able to suppress lung cancer cell viability and invasion, which may occur via the modulating of MCRS1, E-cadherin and vimentin expression. These findings suggest that miR-129-5p may be a potential biomarker and/or treatment strategy for lung cancer.
\end{abstract}

\section{Introduction}

Lung cancer has become one of the most common malignant tumors with a high mortality rate worldwide (1). Due to

Correspondence to: Dr Wenyi Kang, Institute of Natural Products, Henan University, 115 Ximen Street, Kaifeng, Henan 475001, P.R. China

E-mail: kangwenyi2014@sina.com

${ }^{*}$ Contributed equally

Key words: microRNA-129-5p, lung cancer, proliferation, invasion the lack of efficient early diagnosis, $60-80 \%$ of patients are already in stage III or IV when first diagnosed with lung cancer, which may result in poor prognosis and an increased mortality rate (2). The main clinical issue faced during late stage lung cancer is reoccurrence and metastasis, therefore, studies investigating the mechanisms underlying lung cancer metastasis are of great importance for both the diagnosis and treatment of lung cancer.

MicroRNA (miRNA), which are a class of small non-coding RNAs discovered in various types of organisms, have been reported to participate in diverse biological processes, including cell proliferation, differentiation and cell death, through the regulation of the expression of specific target genes $(3,4)$. miR-129 is a product of two genes, mir-129-1 and mir-129-2, and matured miR-129 consists of three forms, miR-129-5p, miR-129-1-3p and miR-129-2-3p (5). Reduced levels of miR-129 have been associated with various types of cancer, including gastric cancer (6), colorectal cancer (7), esophageal squamous cell carcinoma (8) and bladder cancer (9). However, the effect of miR-129 on lung cancer has yet to be investigated.

The present study, for the first time, investigated the association of miR-129 with lung cancer with the focus on one of the three mature forms of miR-129, miR-129-5p. Firstly, miR-129-5p expression levels were determined in primary lung cancer tissues, adjacent non-cancer tissues and lung cancer cell lines. Subsequently, the effect of miR-129-5p on lung cancer cell viability and invasion and underlying mechanisms were investigated. The results demonstrated that miR-129-5p was decreased in primary lung cancer tissues and cell lines. miR-129-5p was able to suppress the viability and invasiveness of the lung cancer cells, which may have occurred via the downregulation of MCRS1 and vimentin and the upregulation of E-cadherin. The findings of the present study suggest that miR-129-5p may be used in lung cancer diagnosis and/or treatment.

\section{Materials and methods}

Samples. A total of 20 patients with primary lung cancers were recruited for the present study from Huanhe Hospital (Kaifeng, China) between 2012 and 2014. The mean age and standard deviation (SD) of the patients was $66.9 \pm 11.2$ years, and $42 \%$ of 
them were women. Lung cancer diagnosis was confirmed by histological examination of cancer tissues. Lung cancer tissues and adjacent non-cancer tissues were obtained and frozen until subsequent use. The protocol involving human specimens was reviewed and approved by the Institutional Review Board of Huanhe Hospital. Written informed consent was obtained from all patients who participated in the study.

Cells and reagents. Human Fetal Lung Fibroblast Cells (MRC-5) and Non-Small Cell Lung Cancer Cells A549 were obtained from ATCC (Manassas, VA, USA) and cultured in Eagle's minimal essential medium and Dulbecco's modified Eagle medium (DMEM), respectively, supplemented with $10 \%$ fetal calf serum (Gibco; Thermo Fisher Scientific, Inc., Waltham, MA, USA) and $100 \mu \mathrm{g} / \mathrm{ml}$ penicillin, and $100 \mu \mathrm{g} / \mathrm{ml}$ streptomycin (Sigma-Aldrich; Merck Millipore, Darmstadt, Germany) at $37^{\circ} \mathrm{C}$ in a $5 \% \mathrm{CO}_{2}$ incubator. hsa-miR-129-5p mimic (stem-loop accession, MI0000252), hsa-miR-129-5p inhibitor (stem-loop accession, MI0000252) and corresponding negative controls were purchased from Thermo Fisher Scientific, Inc. miRNA mimics or inhibitors were transfected into A549 cells using Amaxa Nucleofector (Lonza, Inc., Allendale, NJ, USA) according to the manufacturer's instructions.

miR-129-5p quantification by stem-loop reverse transcription-quantitative polymerase chain reaction ( $R T-q P C R)$. miR-129-5p levels were quantified by stem-loop RT-qPCR, as previously described (10). In brief, miRNA was isolated from lung cancer and non-cancer tissues and cultured cells using a mirVana ${ }^{\mathrm{TM}}$ miRNA Isolation Kit (Thermo Fisher Scientific, Inc.) according to the manufacturer's instructions. Purified miRNA was subsequently reverse transcribed into complementary DNA (cDNA) using a TaqMan MicroRNA Reverse Transcription kit and miRNA-specific stem-loop primers (Applied Biosystems; Thermo Fisher Scientific, Inc.). The RT reaction mixture contained purified RNA (20 ng), $50 \mathrm{nM}$ stem-loop RT primer, 1X RT buffer, $0.25 \mathrm{mM}$ each of deoxynucleotide, $3.33 \mathrm{U} / \mu 1$ reverse transcriptase and $0.25 \mathrm{U} /$ $\mu 1$ RNase inhibitor in a total volume of $7.5 \mu 1$. Th reaction was performed for $30 \mathrm{~min}$ at $25^{\circ} \mathrm{C}, 30 \mathrm{~min}$ at $42^{\circ} \mathrm{C}$ and $5 \mathrm{~min}$ at $85^{\circ} \mathrm{C}$, and then stored at $4^{\circ} \mathrm{C}$. The quantification of miR-129-5p was performed using TaqMan ${ }^{\mathrm{TM}}$ MicroRNA Assay hsa-miR129-5p (Thermo Fisher Scientific, Inc.) according to the manufacturer's protocol. All primers were supplied by the manufacturer. Finally, PCR was performed on an ABI 7300 Real-Time PCR System (Applied Biosystems; Thermo Fisher Scientific, Inc.) to amplify target miR-129-5p and internal control snRNA U6. The reactions were prepared in a $10-\mu 1$ volume containing $0.7 \mu \mathrm{l}$ RT product, $1 \mathrm{X}$ TaqMan ${ }^{\circledR}$ Universal PCR Master Mix (Applied Biosystems; Thermo Fisher Scientific, Inc.), $0.2 \mu \mathrm{M}$ TaqMan ${ }^{\circledR}$ probe, $1.5 \mu \mathrm{M}$ forward primer and $0.7 \mu \mathrm{M}$ reverse primer. The cycling conditions were as follows: $95^{\circ} \mathrm{C}$ for $15 \mathrm{~min}$, and 40 cycles of $94^{\circ} \mathrm{C}$ for $15 \mathrm{sec}, 55^{\circ} \mathrm{C}$ for $30 \mathrm{sec}$ and $72^{\circ} \mathrm{C}$ for $30 \mathrm{sec}$. All reactions were performed in triplicate. The expression of miR-129-5p was normalized to that of U6. The $2^{-\Delta \Delta C q}$ method (11) was adopted for quantification of the relative miRNA expression using RealTime StatMiner ${ }^{\circledR}$ software version 5.0 (Thermo Fisher Scientific, Inc.).
Table I. Primers for reverse transcription-quantitative polymerase chain reaction.

\begin{tabular}{ll}
\hline Gene & \multicolumn{1}{c}{ Primer sequence $\left(5^{\prime} \rightarrow 3^{\prime}\right)$} \\
\hline MCRS1 & F: GGGCTGCTAGATTCATCCCTG \\
& R: GGAGGAGCTTCTCCGTTAGG \\
E-cadherin & F: CGAGAGCTACACGTTCACGG \\
& R: GGGTGTCGAGGGAAAAATAGG \\
Vimentin & F: GACGCCATCAACACCGAGTT \\
& R: CTTTGTCGTTGGTTAGCTGGT \\
GAPDH & F: GAAGGTGAAGGTCGGAGTC \\
& R: GAAGATGGTGATGGGATTTC
\end{tabular}

MCRS1, microspherule protein 1; F, forward; R, reverse.

Cell viability assay. The effect of miR-129-5p on lung cancer cell viability was determined by MTT assay as previously described with modifications (12). In brief, A549 cells $\left(10^{4}\right.$ cells/well $)$ were first treated with or without miR-129-5p mimic or inhibitor or corresponding negative controls for $24 \mathrm{~h}$, and then cells were washed with PBS and stained with Vybrant ${ }^{\circledR}$ MTT assay kit (Life Technologies; Thermo Fisher Scientific, Inc.) according to the manufacturer's instructions. Next, MTT (10 $\mu \mathrm{l}$ of a $12-\mathrm{mM}$ MTT solution) was added to each well containing $100 \mu \mathrm{l}$ medium, and the plate was incubated at $37^{\circ} \mathrm{C}$ for $4 \mathrm{~h}$. The formazan crystals were dissolved in an SDS-HCl solution (0.01 M HCl and $1 \mathrm{mg}$ SDS). Following MTT staining, optical density was read at $570 \mathrm{~nm}$. Medium was used as negative control, while mock-treated cells served as background control.

Cell invasion assay. The effect of miR-129-5p on lung cancer cell invasion was measured using a Transwell system, as previously described with modifications (13). In brief, a Transwell insert (pore size, $8 \mathrm{~mm}$; Corning Inc., Corning, NY, USA) was first coated with $1 \mathrm{mg} / \mathrm{ml}$ Matrigel (BD Biosciences, San Jose, CA, USA) and cells with or without miR-129-5p mimic or inhibitor treatment were seeded onto the Matrigel while the bottom chambers of the Transwell plate were filled with complete culture DMEM. The plate was subsequently incubated at $37^{\circ} \mathrm{C}$ for $18 \mathrm{~h}$. Following incubation, the medium in the inserts with Matrigel coating were removed and the Matrigel was fixed with $4 \%$ paraformaldehyde and stained with $0.1 \%$ crystal violet. Following staining, the cells that had migrated to the lower surface of the Transwell inserts were counted under a microscope.

$R T-q P C R$. A549 cells with or without miR-129-5p mimic or inhibitor treatment were collected and washed with PBS. Total RNA was extracted using RNeasy kit (Qiagen, Inc., Valencia, CA, USA) according to the manufacturer's protocol. Purified RNA was treated with DNase to remove genomic DNA contamination, and then reverse transcribed into cDNA using a cDNA Synthesis kit (Takara Biotechnology Co., Ltd., Dalian, China) containing TaKaRa Ex Taq Hot Start DNA Polymerase (Takara Biotechnology Co., Ltd.), according to the manufacturer's protocol. Subsequently, microspherule protein 1 (MCRS1), 
A

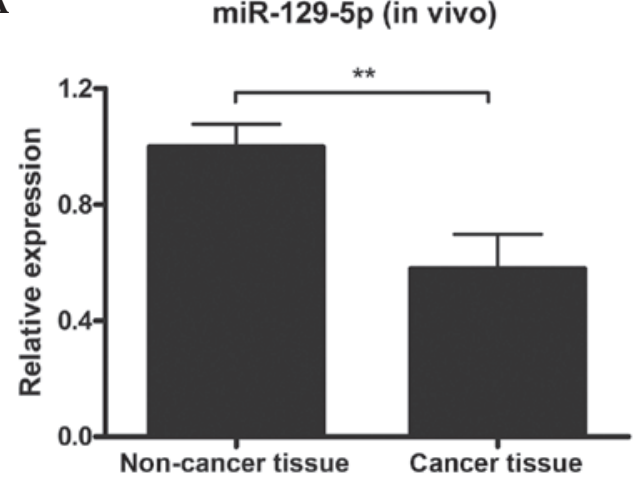

B

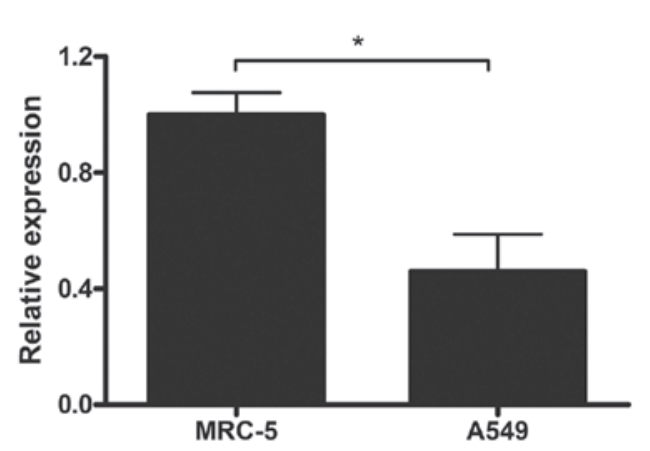

Figure 1. miR-129-5p expression levels in primary tissues (in vivo) and cell lines (in vitro). (A) Primary lung cancer tissues and corresponding adjacent non-cancer tissues were collected from 20 patients and miR-129-5p levels were determined by stem-loop RT-qPCR. All samples were performed in triplicate. (B) Normal human lung fibroblast cells MRC-5 and non-small cell lung cancer cells A549 were collected and miR-129-5p expression levels were determined by stem-loop RT-qPCR. Data are presented as the mean \pm standard deviation of three independent experiments. ${ }^{*} \mathrm{P}<0.05$; ${ }^{* *} \mathrm{P}<0.01$. RT-qPCR, reverse transcription-quantitative polymerase chain reaction.

E-cadherin, vimentin and the internal control, GAPDH, were amplified using a SYBR Green system (Applied Biosystems; Thermo Fisher Scientific, Inc.). The PCR contained 1X RealTime PCR Master Mix containing SYBR Green (Applied Biosystems; Thermo Fisher Scientific, Inc.), $0.2 \mu \mathrm{M}$ primer set, 1X ROX Reference Dye (Applied Biosystems; Thermo Fisher Scientific, Inc.), 1 U DNA polymerase and $5 \mu \mathrm{g}$ cDNA template in a total volume of $20 \mu \mathrm{l}$. The cycling conditions were as follows: $95^{\circ} \mathrm{C}$ for $15 \mathrm{~min}$, followed by 40 cycles of $94^{\circ} \mathrm{C}$ for $15 \mathrm{sec}, 55^{\circ} \mathrm{C}$ (for MCRS1 and GAPDH) or $57^{\circ} \mathrm{C}$ (for E-cadherin and vimentin) for $30 \mathrm{sec}$ and $72^{\circ} \mathrm{C}$ for $30 \mathrm{sec}$. The reaction was performed on an ABI 7300 Real-Time PCR System (Applied Biosystems; Thermo Fisher Scientific, Inc.). All reactions were performed in triplicate. The messenger RNA (mRNA) levels of target genes were normalized to that of GAPDH. The $2^{-\Delta \Delta \mathrm{Cq}}$ method was adopted for quantification of the relative miRNA expression using RealTime StatMiner ${ }^{\circledR}$ software (Thermo Fisher Scientific, Inc.). Primers used for the amplification are listed in Table I.

Western blot. A549 cells with or without miR-129-5p mimic or inhibitor treatment were collected, washed with PBS and lysed with radioimmunoprecipitation assay solution supplemented with protease inhibitor cocktail (Roche Diagnostics, Basel, Switzerland) overnight at $4^{\circ} \mathrm{C}$. Following centrifugation at $10,000 \times \mathrm{g}$ for $10 \mathrm{~min}$ at $4^{\circ} \mathrm{C}$, the supernatants were collected. Cell lysates containing $20 \mu \mathrm{g}$ protein were separated by $12 \%$ SDS-PAGE and transferred onto a polyvinylidene difluoride membrane. Non-specific binding sites on the membrane were blocked with 5\% non-fat milk in PBST for $2 \mathrm{~h}$ at room temperature. Following three washes with PBST (5 min each), the membrane was subsequently incubated with primary antibodies for $2 \mathrm{~h}$ at room temperature. The following primary antibodies were used: Anti-MCRS1 (dilution, 1:1,000; sc-376569; Santa Cruz Biotechnology, Inc., Dallas, TX, USA), anti-E-cadherin (dilution, 1:1,000; \#3195; Cell Signaling Technology, Inc., Danvers, MA, USA), anti-vimentin (dilution, 1:1,000; \#3932; Cell Signaling Technology, Inc.) and anti-GAPDH (dilution, 1:1,000; sc-365062; Santa Cruz Biotechnology, Inc.). Following washing, the membrane was incubated with horseradish peroxidase (HRP)-conjugated secondary antibodies for
$1 \mathrm{~h}$ at room temperature. The following secondary antibodies were used: Goat anti-mouse immunoglobulin G (IgG)-HRP (sc-2005) and goat anti-rabbit-IgG-HRP (sc-2030). Both antibodies were purchased from Santa Cruz Biotechnology, Inc. and were diluted 1:10,000. Following extensive washes, immune-bands on the membrane were visualized with an enhanced chemiluminescent substrate reagent kit (Thermo Fisher Scientific, Inc.) under a charge-coupled device camera (Alpha Innotech Corp., San Leandro, CA, USA).

Statistical analysis. Data were expressed as mean \pm SD in the present study. Statistical analysis was performed using Graphpad Prism 4.01 (GraphPad Software, Inc., La Jolla, CA, USA). For comparisons between two groups, student's t-test was used. For comparisons among more than three groups, one-way analysis of variance with Student-Newman-Keuls post-test was adopted. $\mathrm{P}<0.05$ was considered to indicate a statistically significant difference.

\section{Results}

miR-129-5p levels are decreased in lung cancer cells and tissues. In order to determine whether miR-129-5p levels were altered in lung cancer tissue, lung cancer tissue samples and adjacent non-cancer tissue samples were harvested from 20 patients with primary lung cancers and the miR-129-5p expression levels in the samples were detected by stem-loop RT-qPCR. The results demonstrated that miR-129-5p expression levels in cancer tissues were significantly decreased, as compared with non-cancer tissues ( $\mathrm{P}<0.01$; Fig. 1A). Subsequently, miR-129-5p expression levels in lung cancer (A549) and normal lung (MRC-5) cell lines were measured. Consistent with the results observed in clinical tissue samples, the A549 lung cancer cell line exhibited significantly reduced miR-129-5p expression levels, compared with the MRC-5 normal lung cell line $(\mathrm{P}<0.05$; Fig. 1B).

miR-129-5p suppresses lung cancer cell proliferation. Whether altered miR-129-5p expression levels in lung cancer cell may have implications on cancer progression was subsequently investigated. The A549 lung cancer cell line was 


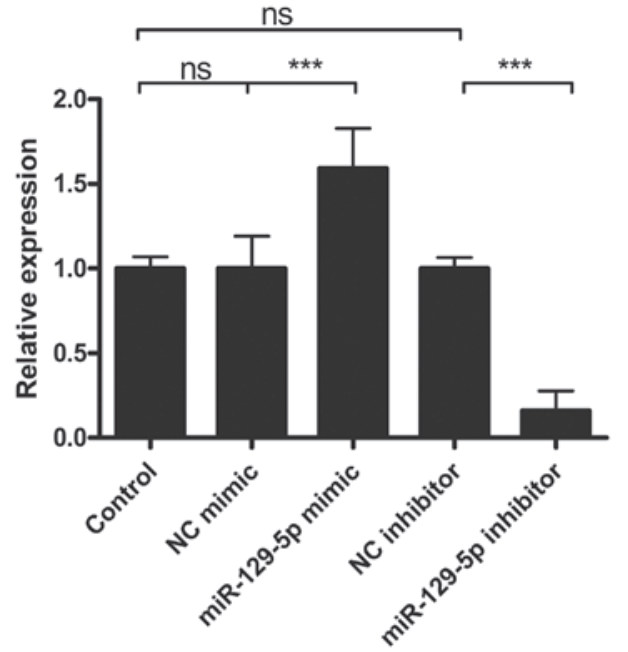

Figure 2. Efficacy of miR-129-5p mimic and inhibitor. A549 cells were treated with or without miR-129-5p mimic or inhibitor or corresponding NC controls for $24 \mathrm{~h}$. Total miRNAs were extracted and miR-129-5p levels were determined by reverse transcription-quantitative polymerase chain reaction analysis. Data are presented as the mean \pm standard deviation of three independent experiments. ${ }^{* * *} \mathrm{P}<0.001$. ns, not significant; $\mathrm{NC}$, negative control.

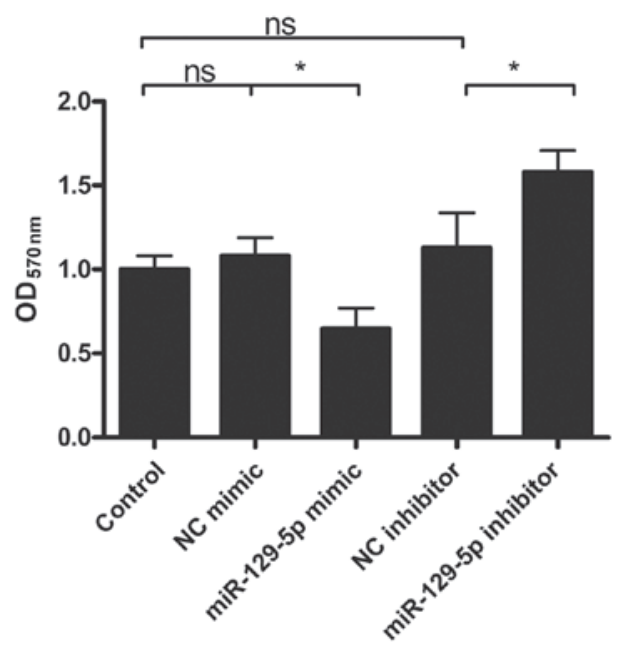

Figure 3. Effect of miR-129-5p on lung cancer cell viability. A549 cells were first treated with or without miR-129-5p mimic or inhibitor and then cells were washed and stained with MTT solution. The OD of the stained cell suspension was determined at $570 \mathrm{~nm}$. Data are presented as the mean \pm standard deviation of three independent experiments. ${ }^{*} \mathrm{P}<0.05$. ns, not significant; $\mathrm{OD}$, optical density; NC, negative control. used as a model for downstream tests. In vitro modulation of miR-129-5p was achieved by transfection of a miR-129-5p mimic and inhibitor. The efficacy of miR-129-5p mimic and inhibitor was determined by stem-loop RT-qPCR. As shown in Fig. 2, compared with the control group, miR-129-5p expression levels increased in miR-129-5p mimic-transfected cells whereas these levels decreased in miR-129-5p inhibitor-transfected cells. Moreover, the negative control (NC) mimic and $\mathrm{NC}$ inhibitor-transfected cells did not exhibit any apparent changes in miR-129-5p expression levels. These results indicated that miR-129-5p levels may be specifically increased and decreased by miR-129-5p mimic and inhibitor transfection, respectively.

Subsequently, the effect of miR-129-5p on lung cancer cell viability was evaluated. Cells treated with or without miR-129-5p mimic or inhibitor for $24 \mathrm{~h}$ were stained with MTT solution and optical density was measured at $570 \mathrm{~nm}$. The results showed that miR-129-5p mimic-treated cells demonstrated a $35 \%$ decrease in viability, whereas miR-129-5p inhibitor-treated cells exhibited a $58 \%$ increase in cell viability, comparing with that of the control (Fig. 3). Unlike miR-129-5p mimic and inhibitor-treated cells, the NC mimic and NC inhibitor-treated cells exhibited minimal alterations in cell viability (Fig. 3). These results implied that miR-129-5p may suppress the viability of lung cancer cells.

miR-129-5p reduces lung cancer cell invasion. Subsequently, the effect of miR-129-5p on lung cancer cell invasion was also investigated using a well-defined Transwell system. Cells with or without miR-129-5p mimic or inhibitor treatment were loaded onto Matrigel coated Transwell inserts and incubated. Following incubation, the cells that had migrated into the lower surface of the Matrigel were counted. As shown in Fig. 4, compared with cells in the control group, the number of cells that migrated in the miR-129-5p mimic group was significantly reduced $(\mathrm{P}<0.05)$. Contrary to the miR-129-5p mimic group, the miR-129-5p inhibitor group exhibited enhanced cell migration, with a $56 \%$ increase compared with the control group. Cell migration from the NC mimic and NC inhibitor groups remained at similar levels to that of the control group. The present results indicated that miR-129-5p may reduce the invasiveness of lung cancer cells.

miR-129-5p modulates lung cancer cell proliferation and invasion by targeting cancer-related genes MCRS1, E-cadherin and vimentin. The findings of the present study thus far showed that miR-129-5p expression levels were decreased in lung cancer tissues and that miR-129-5p was able to suppress the viability and invasiveness of lung cancer cells in vitro. However, the underlying mechanism is yet to be determined. Consequently, the potential mechanisms were subsequently studied by investigating potential cancer-related miR-129-5p target genes. Bioinformatics analysis using miRWalk 2.0 (14) and miRBase (mirbase.org/) (15) revealed that three genes associated with cancer cell proliferation and invasion were potential miR-129-5p targets: MCRS1, E-cadherin and vimentin. MCRS1, which is a gene associated with disease, including pigmented basal cell carcinoma and ampulla of vater carcinoma, has been reported to modulate transcription repressor activity of DAXX (16). Vimentin is a type III intermediate filament that is often used as a marker for cells undergoing epithelial-to-mesenchymal transition during metastatic progression $(17,18)$. E-cadherin, a type I transmembrane protein, has important roles in cell adhesion and a lack of this protein has been shown to result in enhanced cell migration activity (19). The present study investigated the effect of miR-129-5p on target gene expression at both the mRNA and protein levels. As shown in Fig. 5A and B, miR-129-5p mimic treatment was able to reduce the mRNA expression levels of MCRS1 and vimentin, whereas it increased the levels of E-cadherin. Conversely treatment with miR-129-5p elevated the expression levels of MCRS1 and vimentin but lowered 
A

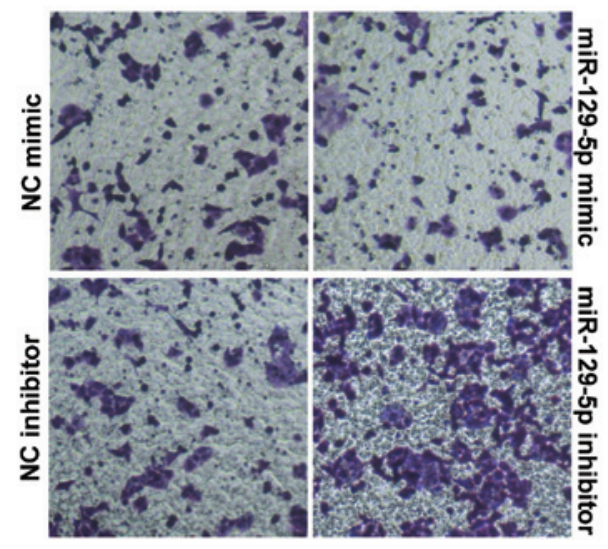

B

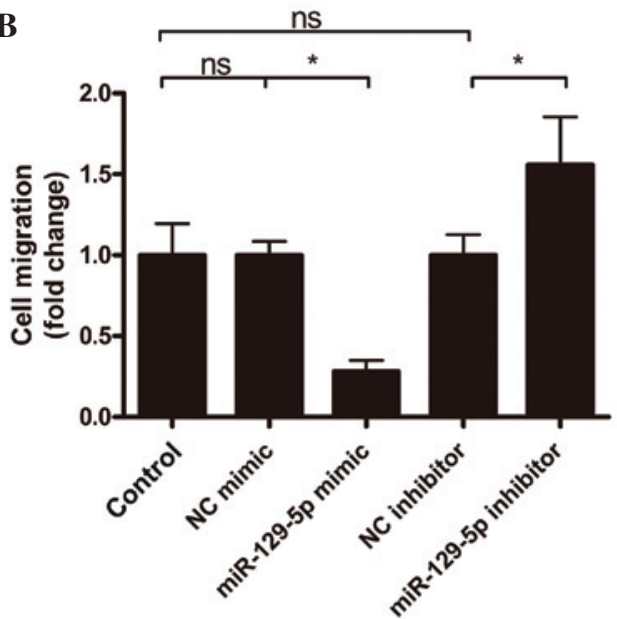

Figure 4. Effect of miR-129-5p on lung cancer cell invasion. A549 cells were treated with or without miR-129-5p mimic or inhibitor, and cell invasion capability was subsequently tested using a Matrigel-coated Transwell system. (A) Representative images and (B) quantitative data are shown. Data are presented as the mean \pm standard deviation of three independent experiments. ${ }^{*} \mathrm{P}<0.05$. NC, negative control; ns, not significant.

A

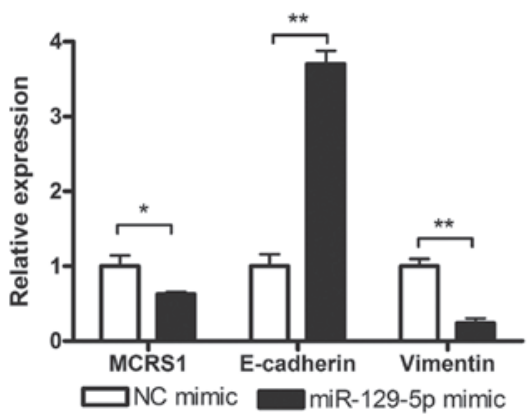

B

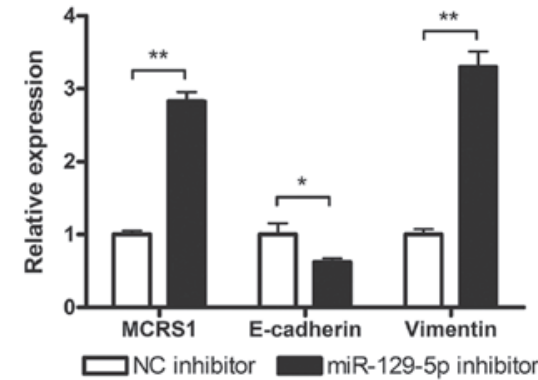

C

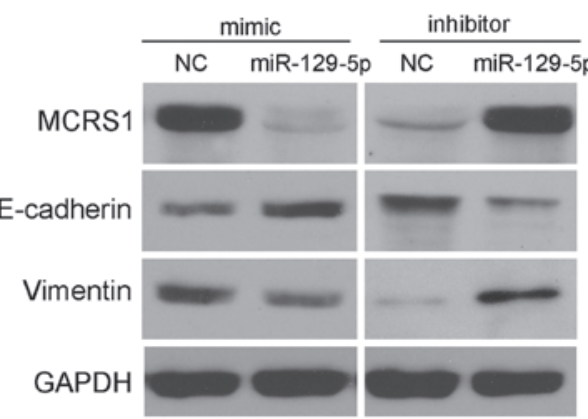

Figure 5. miR-129-5p modulation of MCRS1, E-cadherin and Vimentin mRNA and protein expression levels. A549 cells were treated (A) with or without miR-129-5p mimic or (B) with or without miR-129-5p inhibitor and mRNA levels of MCRS1, E-cadherin and Vimentin were subsequently determined by reverse transcription-quantitative polymerase chain reaction analysis. Data are presented as the mean \pm standard deviation of three independent experiments. ${ }^{*} \mathrm{P}<0.05 ;{ }^{* *} \mathrm{P}<0.01$. (C) A549 cells were treated with or without miR-129-5p mimic or inhibitor and protein levels of MCRS1, E-cadherin and Vimentin were subsequently determined by western blot analysis. Representative results of three independent experiments are shown. MCRS1, microspherule protein 1 ; NC, negative control.

E-cadherin levels. Similar results were observed in the determination of protein expression levels by western blot analysis (Fig. 5C). These results indicated that miR-129-5p successfully modulate the expression of MCRS1, E-cadherin and vimentin on both mRNA and protein levels.

Taken together, the findings of the present study demonstrated that miR-129-5p was decreased in primary lung cancer tissues and cell lines. miR-129-5p could suppress the viability and invasiveness of the lung cancer cells, which may occur via the downregulation of MCRS1 and vimentin and the upregulation of E-cadherin. These results suggest that miR-129-5p may potentially be used in lung cancer diagnosis and/or treatment.

\section{Discussion}

The association of miRNA with human cancer has been studied in many different types of cancer. The significance of miRNA expression profiles has made them valuable in the classification, diagnosis, prognosis and treatment of 
various types of human cancer (20). miR-129, which is one member of the large miRNA family, has been reported to be decreased in various cancer tissues and cell lines (6-9). Previous research also discovered that miR-129-1-3p and miR-129-2-3p in gastric juice may have potential as a biomarker in gastric cancer screening (21). Despite the extensive research of miR-129 in various types of cancer, the study of this miRNA in lung cancer has scarcely been investigated (22). The present study, for the first time, investigated miR-129-5p expression levels in lung cancer tissue and cell lines in order to elucidate its effect on the viability and invasiveness of lung cancer cells. The present results have shown that miR-129-5p was significantly decreased in both primary lung cancer tissues and the lung cancer cell line. Furthermore, this research also revealed that miR-129-5p was able to suppress the viability and invasion capacity of lung cancer cells, which was likely to have been achieved through the modulation of the expression of three miR-129 target genes: MCRS1, E-cadherin and vimentin.

Due to the existence of tissue-specific differences, each type of tumor is unique, which results in diverse miRNA signaling and regulation pathways in different types of cancer (23). It has been reported that miR-129 targets SOX4 in gastric cancer $(24,25)$, GALNT1 in bladder cancer (9), APC in laryngeal squamous cell carcinoma (26) and Rab11 in human esophageal squamous cell carcinoma (27). However, in lung cancer, there has been minimal published research on miR-129 targeted genes (22). The present study utilized bioinformatics analysis to identify three potential target genes for miR-129 (MCRS1, E-cadherin and vimentin). Further research indicated that miR-129-5p was able to regulate the expression of these three genes at both the mRNA and protein levels. Although other possible mechanisms may exist, we hypothesize that the regulation of MCRS1, E-cadherin and vimentin expression by miR-129-5p is one of the mechanisms by which this miRNA suppresses the proliferation and invasion of lung cancer cells. Further investigation into the effect of MCRS1, E-cadherin and vimentin on lung cancer progression as well the detailed mechanism underlying miR-129 regulation of the three cancer-related genes is required.

miR-129 is transcribed from two genes (mir-129-1 and mir-129-2) and pre-miR-129s are edited into three mature forms: miR-129-5p, miR-129-1-3p and miR-129-2-3p (5). In the present study, due to the limited reagents available, only one form of the three, miR-129-5p, was investigated. Given that the other two forms of miR-129 have been described to be involved in other types of cancer, it would be interesting to investigate if miR-129-1-3p and miR-129-2-3p are also associated in lung cancer progression and through what pathway.

miRNA, due to their close association with certain types of cancer, have been studied and used as diagnosis biomarkers and treatment targets (28-32). The present results did not only indicate that miR-129 was significantly reduced in primary lung cancer tissues and cell lines, but also revealed that miR-129 was closely associated with lung cancer progression, implying that it may also have great potential as a diagnostic and/or prognostic biomarker, and even a treatment strategy, for lung cancer. Furthermore, our group have also discovered that miR-129 had some impacts on lung cancer cell resistant to drugs (data not shown). Further research to fully elucidate the effect of miR-129 on lung cancer and or other types of cancer or diseases is required.

\section{References}

1. Jemal A, Siegel R, Xu J and Ward E: Cancer statistics, 2010. CA Cancer J Clin 60: 277-300, 2010.

2. Jemal A, Bray F, Center MM, Ferlay J, Ward E and Forman D: Global cancer statistics. CA Cancer J Clin 61: 69-90, 2011.

3. Lagos-Quintana M, Rauhut R, Lendeckel W and Tuschl T: Identification of novel genes coding for small expressed RNAs. Science 294: 853-858, 2001.

4. Ambros V: MicroRNA pathways in flies and worms: Growth, death, fat, stress and timing. Cell 113: 673-676, 2003.

5. Calin GA, Sevignani C, Dumitru CD, Hyslop T, Noch E, Yendamuri S, Shimizu M, Rattan S, Bullrich F, Negrini M and Croce CM: Human microRNA genes are frequently located at fragile sites and genomic regions involved in cancers. Proc Natl Acad Sci USA 101: 2999-3004, 2004.

6. Yu X, Song H, Xia T, Han S, Xiao B, Luo L, Xi Y and Guo J: Growth inhibitory effects of three miR-129 family members on gastric cancer. Gene 532: 87-93, 2013.

7. Bandres E, Agirre X, Bitarte N, Ramirez N, Zarate R, Roman-Gomez J, Prosper F and Garcia-Foncillas J: Epigenetic regulation of microRNA expression in colorectal cancer. Int J Cancer 125: 2737-2743, 2009.

8. Chen X, Hu H, Guan X, Xiong G, Wang Y, Wang K, Li J, Xu X, Yang K and Bai Y: CpG island methylation status of miRNAs in esophageal squamous cell carcinoma. Int J Cancer 130: 1607-1613, 2012.

9. Dyrskjot L, Ostenfeld MS, Bramsen JB, Silahtaroglu AN, Lamy P, Ramanathan R, Fristrup N, Jensen JL, Andersen CL, Zieger $\mathrm{K}$, et al: Genomic profiling of microRNAs in bladder cancer: miR-129 is associated with poor outcome and promotes cell death in vitro. Cancer Res 69: 4851-4860, 2009.

10. Chen C, Ridzon DA, Broomer AJ, Zhou Z, Lee DH, Nguyen JT, Barbisin M, Xu NL, Mahuvakar VR, Andersen MR, et al: Real-time quantification of microRNAs by stem-loop RT-PCR. Nucleic Acids Res 33: e179, 2005.

11. Livak KJ and Schmittgen TD: Analysis of relative gene expression data using real-time quantitative PCR and the 2(-Delta Delta C(T)) method. Methods 25: 402-408, 2001.

12. Mosmann T: Rapid colorimetric assay for cellular growth and survival: Application to proliferation and cytotoxicity assays. J Immunol Methods 65: 55-63, 1983.

13. Shridhar R, Zhang J, Song J, Booth BA, Kevil CG, Sotiropoulou G, Sloane BF and Keppler D: Cystatin M suppresses the malignant phenotype of human MDA-MB-435S cells. Oncogene 23: 2206-2215, 2004

14. Dweep H, Sticht C, Pandey P and Gretz N: miRWalk-database: Prediction of possible miRNA binding sites by 'walking' the genes of three genomes. J Biomed Inform 44: 839-847, 2011.

15. Griffiths-Jones S, Grocock RJ, van Dongen S, Bateman A and Enright AJ: miRBase: microRNA sequences, targets and gene nomenclature. Nucleic Acids Res (Database issue) 34: D140-D144, 2006.

16. Ren Y, Busch RK, Perlaky L and Busch H: The 58-kDa microspherule protein (MSP58), a nucleolar protein, interacts with nucleolar protein p120. Eur J Biochem 253: 734-742, 1998.

17. Eriksson JE, Dechat T, Grin B, Helfand B, Mendez M, Pallari HM and Goldman RD: Introducing intermediate filaments: From discovery to disease. J Clin Invest 119: 1763-1771, 2009.

18. Leader M, Collins M, Patel J and Henry K: Vimentin: An evaluation of its role as a tumour marker. Histopathology 11: 63-72, 1987.

19. Gumbiner BM: Regulation of cadherin-mediated adhesion in morphogenesis. Nat Rev Mol Cell Biol 6: 622-634, 2005.

20. Calin GA and Croce CM: MicroRNA-cancer connection: The beginning of a new tale. Cancer Res 66: 7390-7394, 2006

21. Yu X, Luo L, Wu Y, Yu X, Liu Y, Yu X, Zhao X, Zhang X, Cui L, Ye G, et al: Gastric juice miR-129 as a potential biomarker for screening gastric cancer. Med Oncol 30: 365, 2013.

22. Xiao Y, Li X, Wang H, Wen R, He J and Tang J: Epigenetic regulation of miR-129-2 and its effects on the proliferation and invasion in lung cancer cells. J Cell Mol Med 19, 2172-2180, 2015.

23. Chiang Y, Song Y, Wang Z, Chen Y, Yue Z, Xu H, Xing C and Liu Z: Aberrant expression of miR-203 and its clinical significance in gastric and colorectal cancers. J Gastrointest Surg 15: 63-70, 2011. 
24. Shen R, Pan S, Qi S, Lin X and Cheng S: Epigenetic repression of microRNA-129-2 leads to overexpression of SOX4 in gastric cancer. Biochem Biophys Res Commun 394: 1047-1052, 2010.

25. Huang YW, Liu JC, Deatherage DE, Luo J, Mutch DG Goodfellow PJ, Miller DS and Huang TH: Epigenetic repression of microRNA-129-2 leads to overexpression of SOX4 oncogene in endometrial cancer. Cancer Res 69: 9038-9046, 2009.

26. Li M, Tian L, Wang L, Yao H, Zhang J, Lu J, Sun Y, Gao X, Xiao H and Liu M: Down-Regulation of miR-129-5p inhibits growth and induces apoptosis in laryngeal squamous cell carcinoma by targeting APC. PLoS One 8: e77829, 2013.

27. Ogawa R, Ishiguro H, Kuwabara Y, Kimura M, Mitsui A, Katada T, Harata K, Tanaka T and Fujii Y: Expression profiling of micro-RNAs in human esophageal squamous cell carcinoma using RT-PCR. Med Mol Morphol 42: 102-109, 2009.

28. Buscaglia LE and $\mathrm{Li} \mathrm{Y}$ : Apoptosis and the target genes of microRNA-21. Chin J Cancer 30: 371-380, 2011.
29. Selcuklu SD, Donoghue MT and Spillane C: miR-21 as a key regulator of oncogenic processes. Biochem Soc Trans 37: 918-925, 2009

30. Tili E, Michaille JJ, Gandhi V, Plunkett W, Sampath D and Calin GA: miRNAs and their potential for use against cancer and other diseases. Future Oncol 3: 521-537, 2007.

31. Toiyama Y, Takahashi M, Hur K, Nagasaka T, Tanaka K, Inoue Y, Kusunoki M, Boland CR and Goel A: Serum miR-21 as a diagnostic and prognostic biomarker in colorectal cancer. J Natl Cancer Inst 105: 849-859, 2013.

32. Volinia S, Calin GA, Liu CG, Ambs S, Cimmino A, Petrocca F, Visone R, Iorio M, Roldo C, Ferracin M, et al: A microRNA expression signature of human solid tumors defines cancer gene targets. Proc Natl Acad Sci USA 103: 2257-2261, 2006. 